wind was raging that day so she snapped a picture of the Red-headed Woodpecker from her kitchen window.

All birds should be as easy to identify as the Red-headed Woodpecker! but then there would be no challenge and that's what makes bird watching so exciting.

\section{CHECK-LIST OF ALBERTA BIRDS}

The fourth edition (1981) of the Alberta bird check-list has recently been published. Three hundred and fifty-two species have been included on the list; an increase of 24 species over the third edition (1975). Of interest to bird enthusiasts is the inclusion of status and abundance codes for each species in the five natural regions: grasslands, parkland, foothills, boreal forest, and Rocky Mountains. All of this information, plus a map of Alberta showing the natural regions, is reproduced in a pocket-sized foldout measuring approximately 4" x 8".

The increase in the number of provincial species over previous check-lists largely reflects the inclusion of a host of accidently occurring species. The 24 new species are: Yellow-billed Loon, Green Heron, Fulvous Whistling Duck, Garganey Teal, Black Scoter, Eskimo Curlew, Surfbird, Sharp-tailed Sandpiper, Curlew Sandpiper, Long-tailed Jaeger, Iceland Gull, Thayer's Gull, Black-legged Kittiwake, Ancient Murrelet, Chimney Swift, Vaux's Swift, Black-chinned Hummingbird, Anna's Hummingbird, Williamson's Sapsucker, Chestnut-backed Chickadee, Pygmy Nuthatch, Eastern Bluebird, Black-throated Gray Warbler, and Black-throated Sparrow.

Check-lists can be purchased (\$1.00) from the Provincial Museum of Alberta Bookshop, 12845 - 102 Avenue, Edmonton, Alberta. T5N OM6. - Dr. Philip H. R. Stepney, Curator of Ornithology, Provincial Museum of Alberta, Edmonton, Alberta. T5N 0M6.

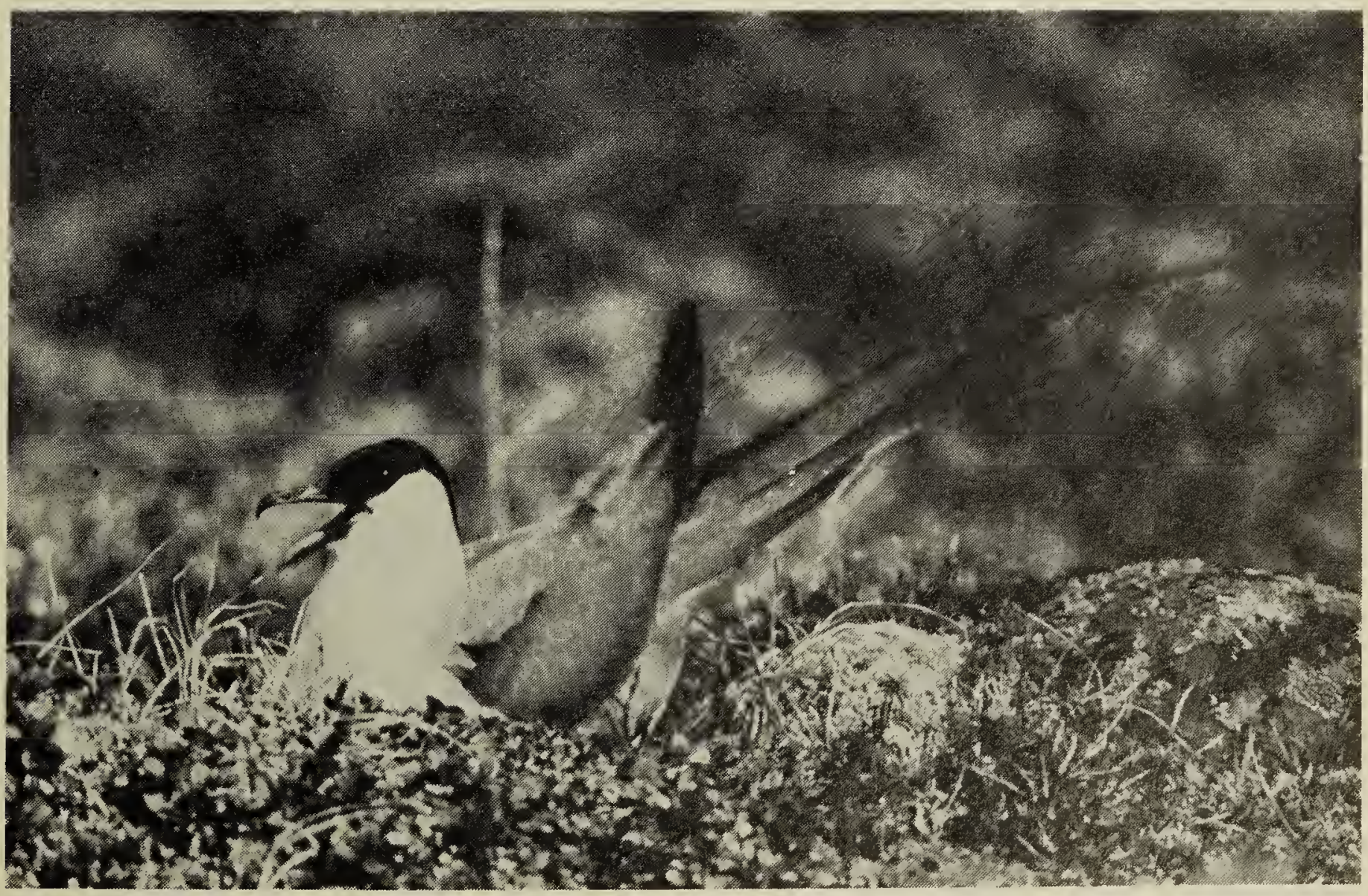

Long-tailed Jaeger, Karrak L., N.W.T.

G.W. Beyersbergen

March 1982. 40(1) 